\title{
45 CONTRIBUTING TO THE FORMATION AND HARMONISATION OF INJURY DATA COLLECTION IN THE PHILIPPINES
}

doi:10.1136/injuryprev-2012-040590w.45

\footnotetext{
${ }^{1,2} \mathrm{M}$ Perez, ${ }^{1,2,3} \mathrm{R}$ Consunji, ${ }^{1} \mathrm{~A}$ Rolloque, ${ }^{1} \mathrm{M}$ Alcantara. ${ }^{1}$ Safe Kids Philippines, Philippines; ${ }^{2}$ Study Group for Injury Prevention, National Institutes of Health, Philippines; ${ }^{3}$ Division of Critical Care \& Trauma, College of Medicine, University of the Philippines, Philippines
}

Background Data on injury has been sporadically collected by different agencies in the Philippines. No policy assigned any particular office or agency to harmonise data from different government and non-government organisations. There were problems on data duplication, increased cost of maintaining the systems and difficulty of sharing.

Aims/Objectives/Purpose Need for baseline data to drive its programmes brought Safe Kids Philippines (SKP) to closely work with the different agencies who could supply reliable data.

Methods SKP aligned itself with the Department of Health (DOH) as part of the Technical Working and Steering Committees for injury data collection and contributed to the formation and development of the Online Electronic Injury Surveillance System. SKP helped to bridge access among $\mathrm{DOH}$, Department of Public Works and Highways (DPWH), and the Metro Manila Development Authority (MMDA) exposing these agencies to existing but overlapping complementary data systems. Issues of ownership, proprietorship and being the principal agency for road crash data slowly eroded as a collegial setting and better communication among the agencies lead to better interaction.

Results Today, the data bases of DOH and DPWH form the base of the Philippine Network on Injury Data Management System (PNIDMS) initiative. MMDA data is currently being integrated. SKP will contribute data analysis to PNIDMS. Other agencies are lined up for inclusion into the PNIDMS.

Significance Synchronised data collection efforts were formalised through a Memorandum of Agreement among $\mathrm{DOH}, \mathrm{WHO}$, Department of Transportation and Communications, UNICEF, MMDA, Land Transportation Office, DPWH with the Philippine National Police, and SKP. 